\title{
Comparison of Antimicrobial Potency Assay of Common Antibiotic Prophylaxis Drugs Recommended in Dentistry for Preventing Infective Endocarditis - An Invitro Study from Chennai, India
}

\author{
Poornachitra ${ }^{1}$, Jayanth Kumar Vadivel2, Geetha R. V. ${ }^{3}$, Subha Manoharan ${ }^{4}$ \\ 1, 2, 3,4 Department of Oral Medicine and Radiology, Saveetha Dental College and Hospital, Chennai, Tamil Nadu, India.
}

\section{ABSTRACT}

\section{BACKGROUND}

Infective endocarditis [IE] prophylaxis is recommended for all dental procedures that involve manipulation of gingival tissue or the periapical region of teeth or perforation of the oral mucosa. The study intended to compare the antimicrobial potency of amoxicillin, cephalexin, and clindamycin against Streptococcus mutans, the common causative organism of dental infections. The objective was to assess the potency of recommended choice of antibiotics and its efficacy among each other in infective endocarditis prophylaxis during dental procedures.

\section{METHODS}

Saliva samples $[\mathrm{N}=20]$ were collected from patients susceptible for IE and Streptococcus mutans was cultured in Infusion Agar. The principle used in this study was based on the Kirby - Bauer disc diffusion Antimicrobial Susceptibility Test [AST] Method and minimum inhibitory concentration [MIC]. In this method, the three HiMedia antibiotic discs of amoxicillin, cephalexin and clindamycin were loaded and assessed for measurable "zone of inhibition" against mutans.

\section{RESULTS}

One-way ANOVA was used to compare the means of zone of inhibition of each disc. The test was statistically significant with $F$ value of 4.093 at $P$ value 0.038 . Post hoc analysis was conducted using Tukey's HSD test as one-way ANOVA was statistically significant. The mean difference of $13.16 \mathrm{~mm}$ between amoxicillin and cephalexin was found to be statistically significant at $\mathrm{P}$ value 0.041 with lower and upper bound at 0.527 and 25.806 respectively. The mean difference of $2.65 \mathrm{~mm}$ between amoxicillin and clindamycin and $-10.50 \mathrm{~mm}$ between cephalexin and clindamycin was not found to be statistically significant.

\section{CONCLUSIONS}

Amoxicillin showed to be more potent among the antibiotics chosen for this study. Clindamycin showed to be a better alternative to cephalexin and could be the first choice in case of patients allergic to penicillin group of drugs.

\section{KEY WORDS}

Antibiotic Prophylaxis, Infective Endocarditis, Antimicrobial Potency, Minimum Inhibitory Concentration [MIC], Antimicrobial Susceptibility Test [AST], Kirby Bauer Disk Diffusion Method

\author{
Corresponding Author: \\ Dr Jayanth Kumar Vadivel, \\ Dept. of Oral Medicine and Radiology, \\ Saveetha Dental College and Hospital, \\ Saveetha Institute of Medical and \\ Technical Sciences, Saveetha University, \\ Chennai, Tamil Nadu, India. \\ E-mail: doctorjayanth@gmail.com
}

DOI: 10.14260/jemds/2021/489

How to Cite This Article:

Poornachitra, Vadivel JK. Geetha RV, et al. Comparison of antimicrobial potency assay of common antibiotic prophylaxis drugs recommended in dentistry for preventing infective endocarditis - an invitro study from Chennai, India. J Evolution Med Dent Sci 2021;10(31):2384-2389, DOI: $10.14260 /$ jemds/2021/489

Submission 25-03-2021,

Peer Review 29-05-2021,

Acceptance 05-06-2021,

Published 02-08-2021.

Copyright (C) 2021 Poornachitra et al. This is an open access article distributed under Creative Commons Attribution License [Attribution 4.0 International (CC BY 4.0)] 


\section{BACKGROUND}

Infective Endocarditis [IE] refers to the infection involving the endocardial surface, commonly involving heart valves, but it can also involve the endocardium or intracardiac devices. ${ }^{1}$ Despite the existing advanced diagnostic aids, therapeutic antibacterial drugs available and preventive treatment strategies in place for anticipated complications, infective endocarditis persists to be the reason for considerable morbidity rate and mortality rate.2,3,4 It had been well documented that mouth had been recognized as entry portal of the microbes in $14-20 \%$ of patients with diagnosed IE. $5,6,7,8$

Streptococcus mutans, a member of the Streptococcus viridans group associated with dental caries, is commonly associated with endocarditis.9,10 $S$. mutans DNA had been commonly detected in cardiovascular specimens, like heart valves and atheromatous plaque. ${ }^{11}$ It had been isolated and characterized by the polymerase chain reaction [PCR] method with DNA sequencing from the samples collected from heart valves and in dental plaque of IE patients. ${ }^{12}$

Around 1955, The American Heart Association [AHA] established its primary protocol for IE prevention associated with treatment procedures done in a dental setting. ${ }^{13}$ The indication for prophylaxis is of late restricted to patients with the increased risk of IE who are to undergo the highest risk of invasive dental treatment procedures. ${ }^{14}$ The American Heart Association Antibiotic Regimens for Cardiac Prophylaxis recommends amoxicillin $2 \mathrm{~g}$ for adults and $50 \mathrm{mg} / \mathrm{kg}$ for children as a single dose $30-60$ min prior to the dental procedure for IE. In case of allergy to the penicillin group of drugs, cephalexin $2 \mathrm{~g}$ for adults and $50 \mathrm{mg} / \mathrm{kg}$ for children or clindamycin $600 \mathrm{mg}$ for adults and $20 \mathrm{mg} / \mathrm{kg}$ for children are recommended as alternatives. 15

Although there is scientific proof of the amoxicillin effectiveness in the prevention of IE after dental procedures, yet the previous results documented in the literature had not confirmed the efficacy of other recommended prophylactic antibiotics. ${ }^{16}$ The Antimicrobial susceptibility testing (AST) is a lab procedure conducted by clinical technician to discover which particular antimicrobial regimen is specifically effective for individual patients. ${ }^{17}$ Minimum inhibitory concentrations (MICs) are defined as the lowest concentrations of an antimicrobial that will inhibit the visible growth of a microorganism after overnight incubation. ${ }^{18}$ Therefore, this in-vitro study was intended to compare the antimicrobial potency of amoxicillin, cephalexin and clindamycin against Streptococcus mutans using AST and MIC. The objective was to assess the potency of recommended choice of antibiotics and its efficacy among each other in infective endocarditis [IE] prophylaxis during invasive dental procedures.

\section{METHODS}

This in vitro study was conducted at the Department of Special Care Dentistry, a unit of Department of Oral Medicine and Radiology in collaboration with Department of Medical
Microbiology in Saveetha dental college and hospital, Chennai. Duration was from October 2020 to November 2020 After getting informed consent, a total of twenty $(\mathrm{N}=20)$ salivary samples based on convenience sampling obtained from both the genders (males $=10$ and females $=10$ ) of age range $18-74$ years were collected from patients with a history of cardiac illness who had reported to the Department of Special Care Dentistry. As per the American Dental Association [ADA] guidelines, these patients may predispose to infective endocarditis and hence required IE antibiotic prophylaxis. ${ }^{19,20}$

\section{Saliva Collection}

The collection procedure of saliva was by spitting method. ${ }^{21}$ In this method, the patients were advised to rinse their mouth in distilled water to remove existing food debris. The unstimulated saliva produced was allowed to pool in the floor of the mouth and the patient spat out into the sterile container for every 60 seconds till the required amount of 20 $\mathrm{ml}$ was attained. This unstimulated saliva was labelled and then transferred to the microbiology laboratory for further analysis by trained laboratory technician.

Antimicrobial Susceptibility Test [AST] and Minimum Inhibitory Concentration [MIC]

AST determines the concentration of an antimicrobial agent needed to inhibit the bacterial growth, for both bactericidal and bacteriostatic agents. ${ }^{22,23}$ Kirby - Bauer Disk Diffusion Susceptibility Test ${ }^{24}$ protocol established by American society for Microbiology had been followed. The principle behind this diffusion test is that the presence or absence of growth around the disks is an indirect measure of the ability of that compound to inhibit that organism. ${ }^{25}$

The saliva samples were plated in brain heart infusion [BHI] agar of Himedia (composition: $12.5 \mathrm{~g} / \mathrm{L}$ HM infusion powder, 5g / L BHI powder, 10g / L Proteose peptone, $2 \mathrm{~g} / \mathrm{L}$ Dextrose (Glucose), $5 \mathrm{~g} / \mathrm{L}$ Sodium chloride, $2.5 \mathrm{~g} / \mathrm{L}$ Disodium hydrogen phosphate, $15 \mathrm{~g} / \mathrm{L}$ Agar, Final $\mathrm{pH}$ ( at $25^{\circ} \mathrm{C}$ ) $7.4 \pm 0.2$ ) according to manufacturer instructions. ${ }^{26}$ The cultural characteristics of Streptococcus mutans were noticed after an incubation at $35-37^{\circ} \mathrm{C}$ for 48 hours as white to grey coloured colonies of an average size of $1 \mathrm{~mm}$ in diameter. ${ }^{27}$ Inoculum was prepared from each culture based on established protocols. ${ }^{24,25}$

AST was performed according to manufacturer's instructions for each patient. The antimicrobial sensitivity discs (SD) [Himedia] each $6 \mathrm{~mm}$ diameter and $30 \mathrm{mcg}$ dosage of amoxicillin, cephalexin and clindamycin were introduced in Streptococcus mutans inoculum on BHI agar plate. The SD introduced were incubated at $37^{\circ} \mathrm{C}$ for 24 hours. Minimum inhibitory concentration [MIC] values characteristically represent the susceptibility of a particular bacterium to a particular antimicrobial. MIC were observed as a "zone of inhibition" surrounding the respective antibiotic discs which were then measured by placing a ruler under the petri plate. The obtained MIC values were compared to known standard values called "breakpoints" to deem the antibiotic sensitive[S] or resistant[R]. 


\section{Statistical Analysis}

The data was tabulated in an excel sheet of Microsoft office Professional Plus 2019, 64 - bit system and formatted. The data analysis was processed using IBM SPSS (statistical package for the social sciences) 23.0 software (SPSS Inc., Chicago, IL., USA). Post hoc analysis was performed using Tukey's HSD test as one-way ANOVA was significant.

\section{RESULTS}

The overall susceptibility interpretation was $S$ (sensitive) to all three antibiotic discs. Table 1 and Figure 2 depicts the zone of inhibition (in $\mathrm{mm}$ ) for the three groups of antibiotics. Regarding amoxicillin, the minimum inhibition zone was 19 $\mathrm{mm}$ and maximum was $39 \mathrm{~mm}$. The mean was $32.33 \pm 7.74$ $\mathrm{mm}$ with lower and upper bound being 24.21 and $40.45 \mathrm{~mm}$ respectively. Regarding cephalexin, the minimum inhibition zone was zero $\mathrm{mm}$ and maximum was $34 \mathrm{~mm}$. The mean was $19.17 \pm 11.69 \mathrm{~mm}$ with lower and upper bound being 6.9 and $31.43 \mathrm{~mm}$ respectively and regarding clindamycin, the minimum inhibition zone was $25 \mathrm{~mm}$ and maximum was 36 $\mathrm{mm}$. The mean was $29.67 \pm 4.08 \mathrm{~mm}$ with lower and upper bound being 25.38 and $33.95 \mathrm{~mm}$ respectively.

The comparison of the "zone of inhibition" (in $\mathrm{mm}$ ) between the three antimicrobial groups is shown in Table 2 . One-way ANOVA was used to compare the means. The test was statistically significant with $F$ value of 4.093 at $P$ value
0.038. Post hoc analysis was performed using Tukey's HSD test as one-way ANOVA was statistically significant (Table 3). The mean difference of $13.16 \mathrm{~mm}$ between amoxicillin and cephalexin was found to be statistically significant at $P$ value 0.041 with lower and upper bound at 0.527 and 25.806 respectively. The mean difference of $2.65 \mathrm{~mm}$ between amoxicillin and clindamycin and - $10.50 \mathrm{~mm}$ between cephalexin and clindamycin was not found to be statistically significant.

\begin{tabular}{|lcccccc|}
\hline Antibiotic Mean & $\begin{array}{c}\text { Standard } \\
\text { Deviation }\end{array}$ & $\begin{array}{c}\text { 95\% CI for Mean } \\
\text { Lower }\end{array}$ & $\begin{array}{c}\text { Upper } \\
\text { Bound }\end{array}$ & MinimumMaximum \\
Bound & & \\
Amoxicillin & 32.33 & 7.74 & 24.21 & 40.45 & 19.0 & 39.0 \\
Cephalexin & 19.17 & 11.69 & 6.90 & 31.43 & 0.0 & 34.0 \\
Clindamycin & 29.67 & 4.08 & 25.38 & 33.95 & 25.0 & 36.0 \\
\hline
\end{tabular}

Table 1. Zone of Inhibition (in $\mathrm{mm}$ ) for the Three Groups of Antibiotics

\begin{tabular}{|c|c|c|c|c|}
\hline Antibiotic & Mean & Standard Deviation & F Value & P Value \\
\hline Amoxicillin & 32.33 & 7.74 & \multirow{3}{*}{4.093} & \multirow{3}{*}{0.038} \\
\hline Cephalexin & 19.17 & 11.69 & & \\
\hline Clindamycin & 29.67 & 4.08 & & \\
\hline \multicolumn{5}{|c|}{$\begin{array}{c}\text { Table 2. Comparison of Zone of Inhibition (in } \mathrm{mm} \text { ) between the Groups } \\
\text { F Value and P Value Obtained from One Way ANOVA Test }\end{array}$} \\
\hline \multicolumn{5}{|c|}{ P Value $\leq 0.05$ is Statistically Significant } \\
\hline
\end{tabular}

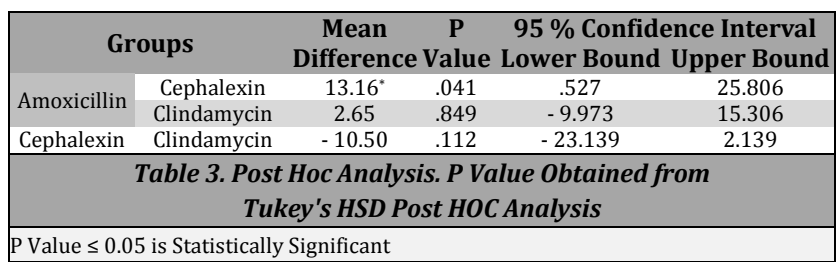

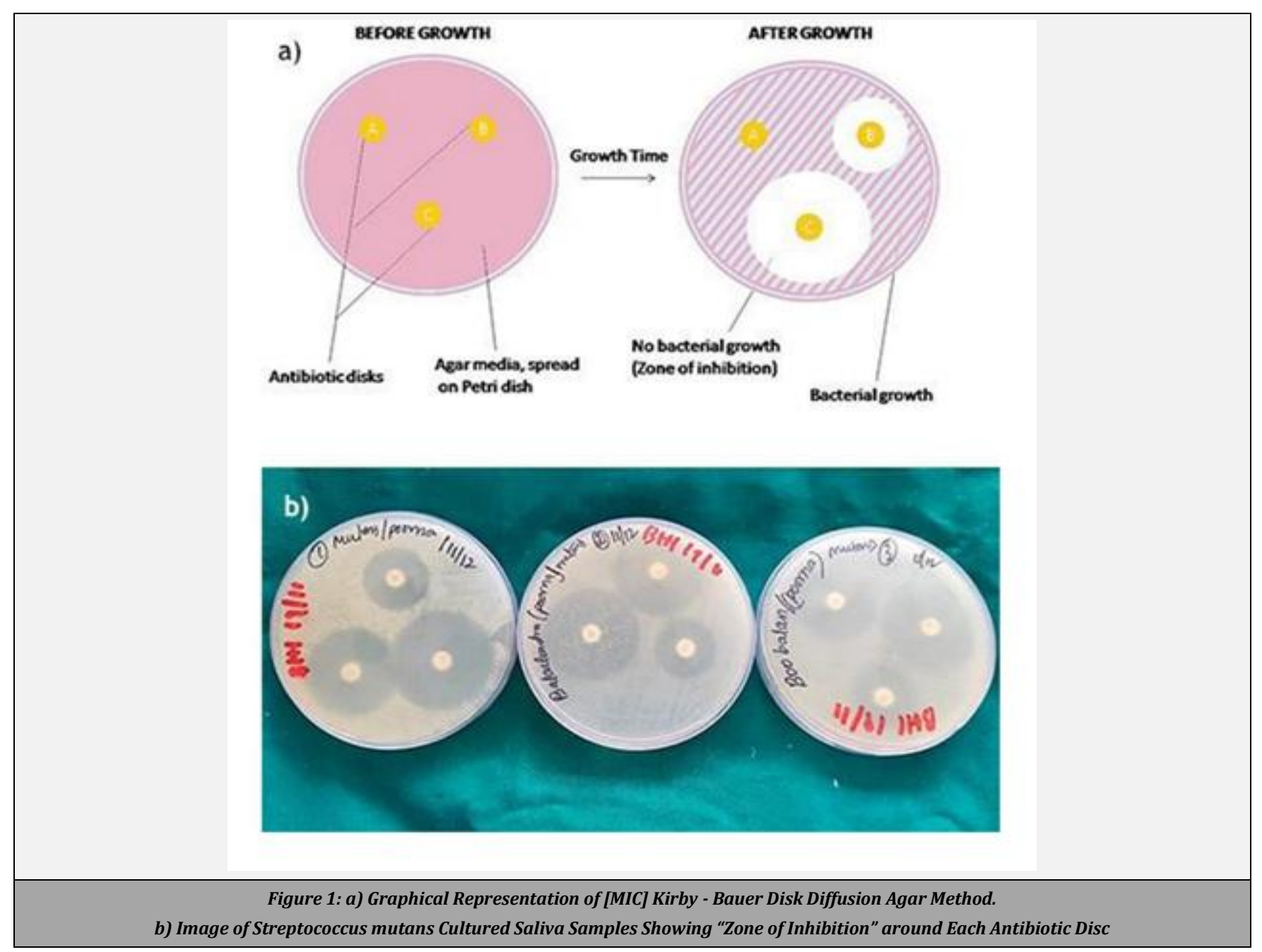




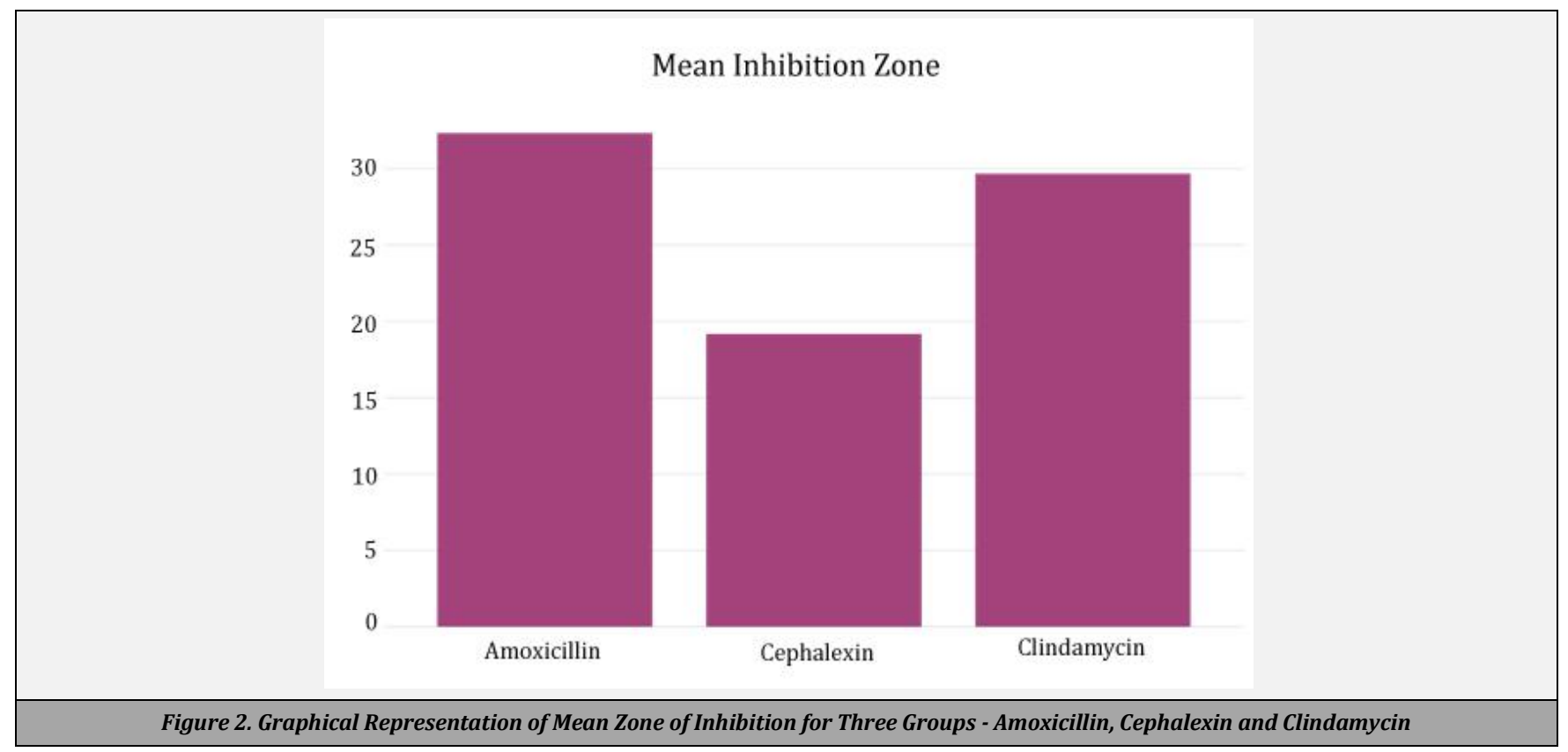

\section{DISCUSSION}

Despite the disagreement about the risk of individuals developing infective endocarditis of oral cavity origin, various expert committees across the countries continue to publish prophylactic regimens for the prevention of infective endocarditis secondary to invasive dental procedures. ${ }^{14}$ Antibiotics (means "against life") are "chemical compounds produced by microorganisms that inhibit the normal regulation of some essential bacterial structure or function with limiting effects on eukaryotic hosts".28 Its efficacy is measured by AST and MIC tests using the Kirby Bauer method.

AST is crucially important; (i) to analyse the preclinical drug sample activity and allows the identification of main lead compound, (ii) to enable possible determination of drug resistance, (iii) to provide estimates in vivo and critically, clinical efficacy when testing compounds in biological matrices simulating infection focal sites, ${ }^{29,30,31,32}$ MICs are used by diagnostic laboratories mainly to confirm resistance, but most commonly used as a research tool to determine the in-vitro activity of new antimicrobials, and data from such studies have been used to determine MIC breakpoints. ${ }^{18}$ The susceptibility Test Interpretive Criteria (STIC), also called "breakpoints," are used to determine the optimal dose of antibacterials necessary for treating the underlying causative primary infection. ${ }^{33}$ The utilization of the Kirby - Bauer disk diffusion susceptibility test is to determine the sensitivity and / or resistance of harmful aerobic bacteria and facultative anaerobes to numerous antimicrobial compounds for the purpose of aiding a diagnostician in choosing better possible treatment options for their patients. ${ }^{25}$

The meta analysis of conducted prior trials indicate that though prophylactic antibiotic coverage is effective in reducing bacteraemia, yet case-control studies conclude that this may not necessarily translate into a significant benefit for low-risk category of patients. ${ }^{14}$ In IE prevention, interdisciplinary interaction of specialists (cardiologists, cardiac surgeons, dentists, etc.) is important, as well as informing high-risk patients about the need for antibiotic prophylaxis during invasive procedures. ${ }^{34}$ Regarding the efficacy of amoxicillin in the prevention of infective endocarditis, $80 \%$ reduction of post-extraction bacteraemia was reported. ${ }^{35}$ Among children, $50 \mathrm{mg} / \mathrm{kg}$ of body weight of amoxicillin significantly reduced bacteraemia secondary to the tooth restoration procedures and oral hygiene measures (from $20 \%$ to $6 \%$ ), and tooth extractions (from $76 \%$ to 15 \%). ${ }^{36}$

Interestingly, The National Institute for Health and Care Excellence [NICE] guidelines have stated "Antibiotic prophylaxis against infective endocarditis is not recommended routinely for people undergoing dental procedures" ${ }^{37}$ This however encourages the use of antibiotic prophylaxis based on clinical judgment in appropriate individual cases though not for all cases based on the recommendation by the patient's cardiologist.

In our study, the mean difference of $13.16 \mathrm{~mm}$ between amoxicillin and cephalexin was found to be statistically significant at $P$ value 0.041 with lower and upper bound at 0.527 and 25.806 respectively. The mean difference of 2.65 $\mathrm{mm}$ between amoxicillin and clindamycin and $-10.50 \mathrm{~mm}$ between cephalexin and clindamycin was not found to be statistically significant. The overall susceptibility interpretation of amoxicillin, cephalexin and clindamycin was $\mathrm{S}$ (sensitive / susceptible) to all three antibiotic discs. This finding is similar to the findings of Chun et al. ${ }^{38}$ and Dhotre et al. ${ }^{39}$ Amoxicillin still continues to be the antibiotic of choice for the prevention of IE according to our study. This result is similar to the findings of Diz Dios et al. ${ }^{40}$ where the study concluded that among 68 regimens scrutinized for 24 common bacterial infections in India, the costliest drug regimen was for infective endocarditis, with INR 3912 for generic and INR 11823.84 for median branded prescription and also amoxicillin was the cost effective antibiotic available. ${ }^{41}$ This might also be an additional reason for its common prescription in IE prevention.

Our study also shows better potency of clindamycin similar to amoxicillin than cephalexin. Clindamycin is the prophylactic antibiotic of choice for patients with a penicillin 
allergy.42,43 Previous studies have demonstrated that amoxicillin and clindamycin taken by oral route of absorption provide high serum concentrations in the first and second hours after ingestion (15 and $25 \mathrm{mg} / \mathrm{L}$, and 4.5 and $4.8 \mathrm{mg} /$ $\mathrm{L}$, respectively), with high levels at $4-6 \mathrm{hrs}$ (5 $\mathrm{mg} / \mathrm{L}$ and 2 $\mathrm{mg} / \mathrm{L}$, respectively), and detectable levels still present after 9 - $10 \mathrm{hrs}\left(0.7 \mathrm{mg} / \mathrm{L}\right.$ and $0.2 \mathrm{mg} / \mathrm{L}$, respectively). ${ }^{44}$ considering the fact that the bacterial growth in the vegetation commences significantly at around 4 hours after the infection onset, it has been postulated that the extended presence of amoxicillin and clindamycin in the bloodstream probably ends with activation of other host defense immunity mechanisms. ${ }^{45,46}$

The advantage of our study was its reproducibility as it had been demonstrated under standard settings by standard protocols.

\section{CONCLUSIONS}

Our study had produced results similar to previous studies that amoxicillin places itself as an indispensable gold standard antibiotic in prophylaxis against IE. And in case of patients who are allergic to penicillin group of drugs, Clindamycin should be the first choice of alternative antibiotic among others.

\section{Limitations}

Though the result of our study conforms with previous studies, there exists limitations such that it was an in-vitro study and could not completely simulate clinical conditions. Larger clinical trials are needed to arrive at definitive conclusions. Future studies should incorporate complete simulation of complex oral microbiome and the influence of other microbes in performance of antibiotics. This will enable us to assess if this complexity turns as an added advantage or disadvantage in attaining expected prophylaxis against IE.

Data sharing statement provided by the authors is available with the full text of this article at jemds.com.

Financial or other competing interests: None.

Disclosure forms provided by the authors are available with the full text of this article at jemds.com.

\section{REFERENCES}

[1] Vilcant V, Hai O. Bacterial Endocarditis. In: StatPearls. Treasure Island (FL): StatPearls Publishing 2020.

[2] Heiro M, Helenius $H$, Makila $S$, et al. Infective endocarditis in a Finnish teaching hospital: a study on 326 episodes treated during 1980-2004. Heart 2006;92(10):1457-62.

[3] Tran CT, Kjeldsen K. Endocarditis at a tertiary hospital: reduced acute mortality but poor long term prognosis. Scand J Infect Dis 2006;38(8):664-70.

[4] Smith JM, So RR, Engel AM. Clinical predictors of mortality from infective endocarditis. Int J Surg 2007;5(1):31-4.
[5] Manford M, Matharu J, Farrington K. Infective endocarditis in a district general hospital. J R Soc Med 1992;85(5):262-6.

[6] Sandre RM, Shafran SD. Infective endocarditis: review of 135 cases over 9 years. Clin Infect Dis 1996;22(2):27686.

[7] Hricak V, Kovacik J, Marx P, et al. Etiology and Risk factors of 180 cases of native valve endocarditis. Diagnostic Microbiology and Infectious Disease 1998;31(3):431-5.

[8] Sekido M, Takano T, Takayama M, et al. Survey of infective endocarditis in the last 10 years: analysis of clinical, microbiological and therapeutic features. J Cardiol 1999;33(4):209-15.

[9] McGhie D, Hutchison JG, Nye F, et al. Infective endocarditis caused by streptococcus mutans. Heart 1977;39(4):456-8.

[10] Nomura R, Matayoshi S, Otsugu M, et al. Contribution of severe dental caries induced by streptococcus mutans to the pathogenicity of infective endocarditis. Infect Immun 2020;88(7):e00897-19.

[11] Nakano $K$, Inaba $H$, Nomura $R$, et al. Detection of cariogenic streptococcus mutans in extirpated heart valve and atheromatous plaque specimens. J Clin Microbiol 2006;44(9):3313-7.

[12] Nomura R, Nakano K, Nemoto $\mathrm{H}, \mathrm{F}$ et al. Isolation and characterization of Streptococcus mutans in heart valve and dental plaque specimens from a patient with infective endocarditis. J Med Microbiol 2006;55(Pt 8):1135-40.

[13] Wilson W, Taubert KA, Gewitz M, et al. Prevention of infective endocarditis: guidelines from the American heart association: a guideline from the American heart association rheumatic fever, endocarditis and Kawasaki disease committee, council on cardiovascular disease in the young and the council on clinical cardiology, council on cardiovascular surgery and anesthesia and the quality of care and outcomes research interdisciplinary working group. Circulation 2007;116(15):1736-54.

[14] Tomás I, Álvarez-Fernández M. History of antimicrobial prophylaxis protocols for infective endocarditis secondary to dental procedures. Recent Advances in Infective Endocarditis 2013.

[15] Glick M. Burket's Oral Medicine. 12th edn. USA: PMPH 2015: p. 732.

[16] Carmona IT, Dios PD, Scully C. Efficacy of antibiotic prophylactic regimens for the prevention of bacterial endocarditis of oral origin. J Dent Res 2007;86(12):114259.

[17] Murray PR. Antimicrobial susceptibility tests: testing methods and interpretive problems. Adv Exp Med Biol 1994;349:15-25.

[18] Andrews JM. Determination of minimum inhibitory concentrations. J Antimicrob Chemother 2001;48(Suppl 1):5-16.

[19] Rethman MP, Watters W 3rd, Abt E, et al. Prevention of orthopaedic implant infection in patients undergoing dental procedures. J Am Acad Orthop Surg 2013;21(3):180-9.

[20] Diogenes CMS, Cha BY. AAE Guidance on antibiotic prophylaxis for patients at risk of systemic disease. American Association of Endodontists 2017:1-6 
[21] Navazesh M. Methods for collecting saliva. Ann N Y Acad Sci 1993;694:72-7.

[22] Brown DFJ, Wootton M, Howe RA. Antimicrobial susceptibility testing breakpoints and methods from BSAC to EUCAST. J Antimicrob Chemother 2016;71(1):35.

[23] Sanguinetti M, Posteraro B. Susceptibility testing of fungi to antifungal drugs. J Fungi (Basel) 2018;4(3):110.

[24] Bauer AW, Kirby WM, Sherris JC, et al. Antibiotic susceptibility testing by a standardized single disk method. Am J Clin Pathol 1966;45(4):493-6.

[25] Hudzicki J. Kirby-Bauer disk diffusion susceptibility test protocol. American Society for Microbiology 2009.

[26] Sapkota A. Streptococcus mutans-an overview. Microbe Notes 2021. https://microbenotes.com/streptococcusmutans/ (Accessed: 23 March 2021).

[27] Wormser GP, Stratton C. Manual of Clinical Microbiology. $9^{\text {th }}$ edn. In: Murray PR, Baron EJ, Jorgensen JH, et al, eds. Pfaller Washington, DC: ASM Press 2007: p. 2488. 2008;46:153-3.

[28] Von Döhren H. Antibiotics: actions, origins, resistance. In: Walsh C, ed. Washington, DC: ASM Press 2003: p. 345. Protein Sci 2009;13(11):3059-60.

[29] Breteler KB, Rentenaar RJ, et al. Performance and clinical significance of direct antimicrobial susceptibility testing on urine from hospitalized patients. Scand J Infect Dis 2011;43(10):771-6.

[30] Macia MD, Rojo-Molinero E, Oliver A. Antimicrobial susceptibility testing in biofilm-growing bacteria. Clin Microbiol Infect 2014;20(10):981-90.

[31] Böttger R, Hoffmann R, Knappe D. Differential stability of therapeutic peptides with different proteolytic cleavage sites in blood, plasma and serum. PLoS One 2017;12(6):e0178943.

[32] Haney EF, Straus SK, Hancock REW. Reassessing the host defense peptide landscape. Front Chem 2019;7:43.

[33] Mercer DK, Torres MDT, Duay SS, et al. Antimicrobial susceptibility testing of antimicrobial peptides to better predict efficacy. Front Cell Infect Microbiol 2020;10:326.

[34] Taradin GG, Ponomareva EY, Ignatenko GA, et al. Antibiotic prophylaxis of infective endocarditis: from the history of the concept to modern recommendations (Review). The Russian Archives of Internal Medicine 2020;10(2):119-30.
[35] Vergis EN, Demas PN, Vaccarello SJ, et al. Topical antibiotic prophylaxis for bacteremia after dental extractions. Oral Surg Oral Med Oral Pathol Oral Radiol Endod 2001;91(2):162-5.

[36] Lockhart PB, Brennan MT, Kent ML, et al. Impact of amoxicillin prophylaxis on the incidence, nature and duration of bacteremia in children after intubation and dental procedures. Circulation 2004;109(23):2878-84.

[37] Thornhill MH, Dayer M, Lockhart PB, et al. A change in the NICE guidelines on antibiotic prophylaxis. Br Dent J 2016;221(3):112-4.

[38] Chun S, Huh HJ, Lee NY. Species-specific difference in antimicrobial susceptibility among viridans group streptococci. Ann Lab Med 2015;35(2):205-11.

[39] Dhotre SV, Jahagirdar VL. Susceptibility, resistance and treatment strategy for infections caused by viridans group streptococci-a review. Journal of Krishna Institute of Medical Sciences University 2016;5(4):1-9.

[40] Atal S, Mathur A, Balakrishnan S. Cost of treating bacterial infections in india: a cost minimization analysis to assess price variations. Biomedical and Pharmacology Journal 2020;13(2):765-78.

[41] Palmer NA, Pealing R, Ireland RS, et al. A study of prophylactic antibiotic prescribing in National Health Service general dental practice in England. Br Dent J 2000;188(10):554-8.

[42] Soheilipour S, Dunne SM, Newton JT, et al. Implementation of clinical practice guidelines in dental settings. J Evid Based Dent Pract 2009;9(4):183-93.

[43] Lauber C, Lalh SS, Grace M, et al. Antibiotic prophylaxis practices in dentistry: a survey of dentists and physicians. J Can Dent Assoc 2007;73(3):245.

[44] Dan M, Yampolsky E, Poch F. Serum Concentrations and ex vivo inhibitory/bactericidal activity of clindamycin after administration of two oral dosages. Chemotherapy 1997;43(4):227-31.

[45] Dall L, Keilhofner M, Herndon B, et al. Clindamycin effect on glycocalyx production in experimental viridans streptococcal endocarditis. J Infect Dis 1990;161(6):1221-4.

[46] Fluckiger U, Moreillon P, Blaser J, et al. Simulation of amoxicillin pharmacokinetics in humans for the prevention of streptococcal endocarditis in rats. Antimicrob Agents Chemother 1994;38(12):2846-9. 